\title{
Atividade antimicrobiana de Lactobacillus e Bifodobacterium frente a microrganismos patogênicos "in vitro"
}

\section{Antimicrobial activity of Lactobacillus and Bifidobacterium strains against pathogenic microorganisms "in vitro"}

\author{
Giselle Nobre Costa ${ }^{1 *}$; Helio Hiroshi Suguimoto ${ }^{2}$; \\ Lucia Helena da Silva Miglioranza ${ }^{3}$; Raúl Jorge Hernan Castro Gómez ${ }^{3}$
}

\begin{abstract}
Resumo
Lactobacilos e bifidobactérias apresentam um longo histórico de uso seguro em alimentos, além de apresentarem características de interesse biotecnológico como a inibição de patógenos. Neste trabalho duas linhagens de lactobacilos e uma de bifidobactéria, isoladas do intestino humano, foram avaliadas em testes de difusão em ágar, quanto à capacidade de inibição de microrganismos patogênicos de ocorrência comuns em toxinfecções alimentares. Adicionalmente, foram avaliados os metabólitos produzidos em caldo de cultivo estático e em agitação para simular condições de anaerobiose a aerobiose, respectivamente. As três bactérias, L. acidophilus LA5, L. plantarum DCTA 8420 e B. lactis DCTA 8724 apresentaram capacidade de inibição para $S$. aureus FRI 196 linhagem produtora de toxinas A e D, assim como para B. cereus ATCC 25923, E. coli ATCC 25922 e $S$. Enteritidis, cujos halos de inibição apresentaram em média $24 \mathrm{~mm}$ de diâmetro. No método de difusão em ágar com meio de cultivo concentrado, foi possível observar o efeito do oxigênio sobre a produção de substâncias tóxicas aos microrganismos indicadores, evidenciando que Lactobacillus cultivados em aerobiose, parece produzir metabólitos com maior efeito inibitório, enquanto que, para a linhagem de Bifidobacterium, o efeito foi oposto.
\end{abstract}

Palavras-chave: Bactérias lácticas, atividade antimicrobiana, B. lactis, L. plantarum, L. acidophilus

\begin{abstract}
Lactobacilli and bifidobacteria have a long history of safe use in foods. These bacteria have biotechnological characteristics of interest such as the inhibition of pathogens. In this work, two lactobacilli strain and a bifidobacterium strain isolated from human gut were evaluated concerning to their ability to inhibit pathogenic microorganisms in foods by diffusion agar tests. Moreover, we assessed the metabolites produced in culture broth under static and shaking growth to simulate anaerobiosis and aerobiosis conditions, respectively. L. acidophilus LA5, L. plantarum DCTA 8420 and B. lactis DCTA 8724 showed ability to inhibit $S$. aureus FRI 196, strains producer toxins A and D, as well as B. cereus ATCC 25923, E. coli ATCC 25922 and $S$. Enteritidis, whose inhibition halos reached, on average, $24 \mathrm{~mm}$ in diameter. In the agar diffusion method with concentrated culture medium, it was possible to observe the effect of oxygen on the production of toxic substances. This result showed that cultivation of Lactobacillus under aerobic conditions seems to exert greater inhibitory effect, whereas for Bifidobacterium strain the effect was the opposite.
\end{abstract}

Key words: Lactic acid bacterial, antimicrobial activity, B. lactis, L. plantarum, L. acidophilus

\footnotetext{
${ }^{1}$ Discente, do Programa de Mestrado e Doutorado em Ciência de Alimentos, Dept ${ }^{\circ}$ de Ciência e Tecnologia de Alimentos da Universidade Estadual de Londrina, UEL, Londrina, PR; Prof. Pesquisador do Programa de Mestrado em Ciência e Tecnologia do Leite da Universidade Norte do Paraná, UNOPAR, Londrina, PR. E-mail: gcnobre@gmail.com

2 Prof. Pesquisador do Programa de Mestrado em Ciência e Tecnologia do Leite da Universidade Norte do Paraná, UNOPAR, Londrina, PR. E-mail: helio.suguimoto@unopar.br

${ }^{3}$ Profs. Pesquisadores do Programa de Mestrado e Doutorado em Ciência de Alimentos, Dept ${ }^{\circ}$ Ciência e Tecnologia de Alimentos, UEL, Londrina, PR. E-mail: luciah@uel.br; rcastrog@yahoo.com

* Autor para correspondência
} 


\section{Introdução}

As bactérias do ácido lático (BAL) desempenham um importante papel na produção de alimentos, por favorecerem características sensoriais e tecnológicas, além de promoverem a conservação destes, devido à competição e inibição da microbiota deteriorante e/ou agentes patogênicos (JACOBSEN et al., 1999; NAIDU; CLEMENS, 2000; MADERA et al., 2003).

Historicamente, a indústria de lácteos tem utilizado bactérias lácticas nos mais variados produtos, como culturas iniciadoras ou adjuntas em leites fermentados, queijos e soro de queijo (PRASAD; GODEKER, 1991; MENÉNDEZ et al., 2004). Além disso, muitas destas BAL apresentam características probióticas; uma propriedade cada vez mais valorizada, devido aos efeitos benéficos que estes microrganismos promovem na saúde do seu hospedeiro. $\mathrm{Na}$ indústria de cárneos, BAL são utilizadas para fermentação de embutidos e contribuem no desenvolvimento de sabor, bem como na preservação destes alimentos inibindo microrganismos patogênicos, como Staphylococcus aureus, Listeria monocytogenes, Salmonella spp., Bacillus spp., Pseudomonas spp. e bactérias do grupo coliforme (SCHILLINGER; KARL LUCKE, 1989; GUEDES NETO et al., 2005).

Quanto à eficiência de fermentação o gênero Lactobacillus é o mais difundido, entretanto, Bifidobacterium tem sido muito empregado como cultura adjunta. Ambos os gêneros são comumente associados à promoção de efeitos benéficos. Bifidobactérias (BF) são comumente aceitas como membros do grupo BAL, embora sejam filogeneticamente distantes deste grupo, devido à presença de frutose 6-fosfato fosfocetolase (P6PPK), responsável pela fermentação de hexoses, produção de ácido lático e ácido acético na proporção 2:3, enquanto que no metabolismo de Lactobacillus ocorre principalmente produção de ácido láctico. Além disso, o maior teor (\% em mol) de guanina e citosina no DNA de bifidobactérias, que variam de
55 a $67 \%$, é particularmente diferente do conteúdo do DNA de Lactobacillus, um membro típico de BAL (HOLZAPFEL; STILE, 1997; GOMES; MALCATA, 1999; AKIMOV; SIDARENKA; NOVIK, 2008; COSTA, et al., 2011).

A capacidade de exclusão ou redução de enteropatógenos demonstrada por muitas linhagens de BAL e bifidobactérias é uma das características mais importantes atribuídas a estes microrganismos, do ponto de vista da ciência e tecnologia de alimentos, pois está diretamente relacionada à capacidade de produzir e tolerar elevadas concentrações destes metabólitos, favorecendo a competição com outros microrganismos num dado ecossistema. Em geral este efeito é associado à produção de ácidos orgânicos, bacteriocinas, peptídeos bacterianos ou proteínas ativas (JIN et al., 1997; WALKER; DUFFY, 1998; CLOSE, 2000).

Nos últimos anos, a busca por qualidade de vida associada a hábitos saudáveis como a melhora da alimentação e da saúde de modo geral, promoveu naturalmente o interesse por estes microrganismos, devido aos efeitos benéficos que exercem sobre o metabolismo do hospedeiro, bem como na tecnologia de fermentações. Assim, o mercado de BAL e BF se mantém promissor e é foco de constante investigação. Este trabalho teve como objetivo avaliar as propriedades antagônicas in vitro, de linhagens de Lactobacillus acidophilus comercial, L. plantarum e de Bifidobacterium lactis, isoladas do intestino humano, contra microrganismos patogênicos e avaliar o efeito do oxigênio sobre o metabolismo destas culturas quanto à produção de substâncias inibitórias.

\section{Material e Métodos}

\section{Manutenção e cultivo dos microrganismos}

Foram utilizadas três bactérias, Bifidobacterium lactis (DCTA 8724), Lactobacillus plantarum (DCTA 8420), isoladas de fezes de crianças saudáveis, e avaliadas quanto ao potencial probiótico 
por Pozza (2006) e Lactobacillus acidophilus (LA5/C. Hansen), além de quatro microrganismos indicadores, patogênicos potenciais: Bacillus cereus ATCC 25923, Escherichia coli ATCC 25922, Staphylococcus aureus FRI196 produtor de enterotoxina A e D e Salmonella enterica subsp. enterica serovar Enteritidis, os dois últimos isolados de surtos no Estado do Paraná.

As BAL e BF foram inoculadas em LDR (Leite desnatado reconstituído, esterilizado) 10\%, incubado a $37^{\circ} \mathrm{C} / 24 \mathrm{~h}$. Tal procedimento foi repetido duas vezes utilizando $1 \mathrm{~mL}$ do inóculo anterior para completa ativação da cultura. Promoveu-se diluição seriada utilizando água peptonada tamponada $0,1 \%$ (Oxoid, Cambridge, UK) e contagem de UFC/mL pela técnica de semeadura em profundidade em ágar MRS (De Man Rogosa and Sharpe, Oxoid, Cambridge, UK). As placas foram incubadas a $37^{\circ} \mathrm{C} / 48$ h. Lactobacillus e Bifidobacterium foram cultivadas em aerobiose e anaerobiose (Anaerobac, Probac. São Paulo, Brasil) Os microrganismos patogênicos foram cultivados em ágar Mueller Hinton (Oxoid, Cambridge, UK), plaqueamento em superfície a $37^{\circ} \mathrm{C} / 24 \mathrm{~h}$.

\section{Inibição pelo método de multicamadas}

Utilizou-se metodologia descrita por Bevilacqua et al. (2003) e Garcia (1999), com algumas modificações. Adicionou-se $7 \mathrm{~mL}$ de ágar MRS 1,2\% (P/V), seguido de $7 \mathrm{~mL}$ de ágar MRS 0,8\% $(\mathrm{P} / \mathrm{V})$ inoculado com $1 \mathrm{~mL}$ de cada bactéria (lactobacilos ou bifidobactéria) previamente diluído em água peptonada tamponada, visando atingir contagem não superior à $1 \times 10^{2} \mathrm{UFC} / \mathrm{mL}$. Incubou-se a $37^{\circ} \mathrm{C} / 48 \mathrm{~h}$ em aerobiose. $\mathrm{O}$ mesmo procedimento foi efetuado em anaerobiose (Anaerobac, Probac. São Paulo, Brasil). Após 48 h, adicionou-se sobre o meio semi-sólido $7 \mathrm{~mL}$ de ágar nutriente $0,8 \%(\mathrm{P} / \mathrm{V})$ com $200 \mu \mathrm{L}$ do microrganismo indicador utilizando espalhamento em superfície, cuja contagem foi estabelecida na faixa de $10^{5}$ a $10^{6} \mathrm{UFC} / \mathrm{mL}$. Incubouse em aerobiose por $24 \mathrm{~h}$ a $37^{\circ} \mathrm{C}$ e observou-se presença ou ausência de halos de inibição em volta de cada colônia de BAL ou bifidobactéria.

\section{Inibição pelo método de difusão em ágar}

Para observar o efeito do oxigênio na inibição dos patógenos, as duas linhagens de Lactobacillus e a linhagem de Bifidobacterium foram cultivados em caldo MRS sob agitação, simulando condições de aerobiose (Ae) e cultivo estático em frascos tipo Erlenmeyer vedados com rolhas de borracha visando simular ambiente com ausência de $\mathrm{O}_{2}$ ( An).

Cada frasco foi adicionado com $100 \mathrm{~mL}$ de caldo MRS e inoculado com $10 \%(\mathrm{v} / \mathrm{v})$ de cultivos recentes de $\mathrm{BAL}$ ou $\mathrm{BF}$ e incubado a $37^{\circ} \mathrm{C} / 72 \mathrm{~h}$ nas duas condições descritas anteriormente. Após 72 horas o meio foi centrifugado a $8000 \mathrm{RPM}$ a $5^{\circ} \mathrm{C} / 10$ min. O sobrenadante foi concentrado em liofilizador (BOC Edwards- LP3, S. Paulo, Brasil), reduzindo em 10 vezes o volume. Este material foi utilizado no teste de difusão em ágar. Para efeito de comparação, utilizou-se também este material neutralizado a $\mathrm{pH}$ 7,0 por adição de $\mathrm{NaOH}$ (4 mol/L).

Foram preparados placas de Petri com ágar Mueller Hinton (Oxoid, Cambridge, UK). Espalhou-se $200 \mu \mathrm{L}$ do microrganismo patogênico $\left(10^{5}\right.$ a $\left.10^{6} \mathrm{UFC} / \mathrm{mL}\right)$ em superfície. Foram feitas três perfurações de $6 \mathrm{~mm}$ de diâmetro, nas quais foram adicionados $50 \mu \mathrm{L}$ de cada sobrenadante concentrado, aguardando difusão do material no ágar durante a incubação a $37^{\circ} \mathrm{C} / 24 \mathrm{~h}$. Os halos de inibição formados, foram mensurados utilizando um paquímetro (Tesa, Curitiba, PR). Todos os experimentos foram efetuados em triplicata.

\section{Resultados e Discussões}

As bactérias lácticas e bifidobactéria cultivadas em ágar em condições de aerobiose (Ae) ou anaerobiose (An) inibiram os quatro microrganismos indicadores no teste de antagonismo pelo método de multicamadas, conforme observado pela ausência de crescimento do microrganismo indicador em volta de todas as colônias de BAL ou BF (Tabela 1). 
Tabela 1. Inibição de S. aureus, B. cereus, E. coli e S. Enteritidis por bactérias lácticas e bifidobactéria cultivadas em ágar sob aerobiose ou anaerobiose no teste de multicamadas.

\begin{tabular}{cccccccccc}
\hline & \multicolumn{3}{c}{ S. aureus } & \multicolumn{2}{c}{ B. cereus } & \multicolumn{2}{c}{ E. coli } & \multicolumn{2}{c}{ S. Enteritidis } \\
\cline { 2 - 9 } & Ae & An & Ae & An & Ae & An & Ae & An \\
\hline L. plantarum & + & + & + & + & + & + & + & + \\
L. acidophilus & + & + & + & + & + & + & + & + \\
B. lactis & + & + & + & + & + & + & + & + \\
Controle & - & - & - & - & - & - & - & - \\
\hline
\end{tabular}

Ae: Agitação, condição simulada de Aerobiose, An: Estático, simulação de anaerobiose; ${ }^{+}$Zonas claras com ausência do patógeno em volta da colônias de BAL ou BF; - Ausência de inibição no controle com ágar MRS isento de BAL ou BF

Fonte: Elaboração dos autores.

Relatos do efeito antagônico de BAL ou BF sobre patógenos comuns em alimentos são frequentes alvos de investigação. Pereira e Gómez (2007) relataram inibição de E. coli e $S$. aureus por L. acidophilus, Lahtinem et al. (2007) observaram inibição de S. aureus, Salmonella spp. e E. coli por linhagens de Bifidobacterium, Uraz, Simsek e Maras (2001) e Guedes Neto et al. (2005) relataram a inibição de microrganismos indicadores por BAL isoladas de queijo artesanal e leite cru. Vaughan, Caplice e Looney (1994); Brashears e Durre (1999) e Chioda et al. (2007) também observaram ação antagonista de algumas BAL contra Salmonella spp. e E. coli O157:H7, S. aureus, Listeria inócua e Pseudomonas fragi. Muitos destes autores atribuem o efeito inibitório à produção de ácidos orgânicos, à produção de peróxido dehidrogênio ou bacteriocinas, substâncias características do metabolismo destes microrganismos; daí a importância e interesse da utilização destas bactérias em alimentos e como integrantes da microbiota humana e animal.
Durante a fermentação em meio liquido, o caldo MRS esterilizado, apresentou $\mathrm{pH} 6,5$, os cultivos com BAL e/ou BF atingiram valores médios de 4,3 e 4,1 após 72 horas sob agitação e estático, respectivamente. Quando o meio foi concentrado os valores de $\mathrm{pH}$ tiveram médias de 4,1 e 3,9 para as duas condições avaliadas para quaisquer das três bactérias.

Nos testes de difusão em ágar, os halos formados por ação do sobrenadante concentrado, fermentado por L. acidophilus LA5, L. plantarum DCTA 8420 ou B. lactis DCTA 8724 contra os quatro microrganismos patogênicos são dados na Tabela 2. Nota-se que todas as bactérias produziram substâncias capazes de inibir os patógenos em teste, formando halos de 20 a $32 \mathrm{~mm}$ (Figuras 1, 2 e 3). O teste de difusão em ágar é considerado semi-quantitativo para substâncias puras ou misturas como extratos biológicos (NCCL, 2005), e se mostrou uma alternativa viável para investigar o potencial de inibição destas culturas, sobre microrganismos indicadores.

Tabela 2. Atividade antimicrobiana de substâncias produzidas por BAL e BF em caldo MRS concentrado, cultivado com e sem agitação contra microrganismos indicadores.

\begin{tabular}{lcccccccc}
\hline & \multicolumn{2}{c}{ S. aureus } & \multicolumn{2}{c}{ B. cereus } & \multicolumn{2}{c}{ E. coli } & \multicolumn{2}{c}{ S. Enteritidis } \\
\hline & Ae & An & Ae & An & Ae & An & Ae & An \\
L. acidophilus & 23 & 23 & 30 & 27 & 29 & 25 & 27 & 21 \\
L. plantarum & 26 & 24 & 27 & 26 & 32 & 25 & 26 & 25 \\
B. lactis & 20 & 26 & 25 & 28 & 25 & 26 & 24 & 24 \\
Controle & - & - & - & - & - & - & - & - \\
\hline
\end{tabular}

Ae: Agitação (Aerobiose), An: Estático (Anaerobiose).

Valores do diâmetro dos halos de inibição média de três repetições (mm); - Ausência de inibição

Fonte: Elaboração dos autores. 
Os meios de cultura não concentrados produziram halos menores (dado não mostrado), se comparados ao material concentrado, evidentemente a concentração das substâncias aumentou a efetividade do antagonismo. Adicionalmente, o meio produzido por BAL e BF, concentrado e neutralizado a pH 7,0 não apresentou nenhuma inibição para quaisquer dos patogênicos avaliados (Figura 2B). A neutralização do meio parece inativar a substância inibidora. Indicando que neste caso, a produção de ácidos a partir da fermentação das BAL e BF, parece ser o fator chave no potencial antimicrobiano.

Figura 1. A) Inibição de Salmonella Enteritidis por Lactobacillus acidophilus LA-5; B e C) inibição de E. coli ATCC25922 e Bacillus cereus, respectivamente por L. plantarum DCTA8420 e D) inibição Staphylococcus aureus FRI 196e por Bifidobacterium lactis DCTA8724. Todos os testes BAL e BF cultivadas sob agitação (Ae) e estático (An).

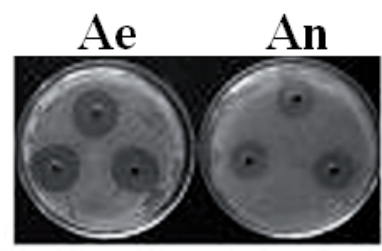

A

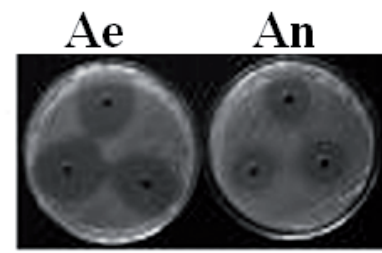

B

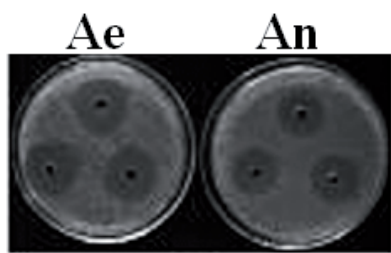

C

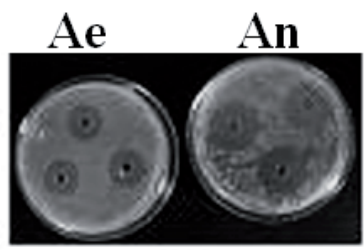

D

Ae: Aerobiose, An: anaerobiose

Fonte: Elaboração dos autores.

A inibição de patógenos por BAL e BF pode ser atribuída à presença de ácidos na forma não dissociada, que deste modo atravessam a membrana celular interferindo na sua permeabilidade e, portanto, inibindo o transporte ativo e promovendo a acidificação do conteúdo celular (CLIVER; MARTH, 1990). Nestes microrganismos, os ácidos láctico e acético são os principais responsáveis pelo efeito antagônico (GUEDES NETO et al., 2005; JIN; MARQUARDT; BAIDOO, 2000).

Lahtinen et al.(2007) estudaram o efeito inibitório de Bifidobacterium isoladas de fezes de indivíduos idosos sobre $S$. aureus e enfatizam que para estas linhagens é mais comum a produção de ácidos orgânicos como antimicrobianos e acrescentam ser incomum a produção de substâncias de outra natureza. A Literatura reporta que a atividade de bacteriocinas não é comumente afetada de forma tão drástica pelo aumento do pH (BEVILACQUA et al., 2003) e que a sua atividade ocorre em $\mathrm{pH}$ de 2 a 10, embora, a efetividade diminua a $\mathrm{pH}$ extremos (BROMBERG et al., 2006).
Quanto ao efeito do oxigênio sobre os cultivos; de modo geral, L. acidophilus e L. plantarum em aerobiose promoveram maior inibição dado à formação de maiores halos, enquanto que o efeito oposto foi observado para o Bifidobacterium lactis (Tabela 2, Figuras 1 e 3). O crescimento das bactérias em agitação ou estático cujas condições simulam ambientes com aerobiose ou anaerobiose parece influenciar no índice de inibição. Condon (1987) sugere algumas rotas metabólicas comuns em BAL em condições de presença ou ausência de oxigênio. Também Sakamoto e Komagata (1996) avaliaram o efeito da aeração na concentração de produtos finais do metabolismo em várias espécies de BAL e observaram a produção de lactato em maior concentração sob anaerobiose, produção de etanol em concentrações iguais ou superiores nos cultivos em aerobiose e anaerobiose respectivamente, e acetato como produto final majoritário para $\mathrm{BAL}$ em aerobiose. 
Figura 2. A) Inibição de $B$. cereus por substâncias produzidas por: 1- L. acidophilus LA5; 2- L. plantarum DCTA 8420; 3- B. lactis DCTA 8724 e B): Mesma análise com substâncias neutralizadas a pH 7,0.

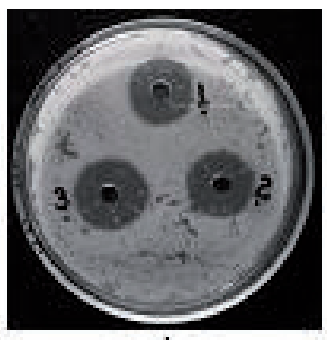

A

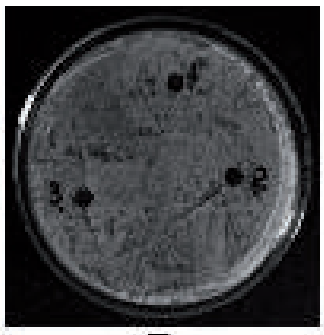

B
Fonte: Elaboração dos autores.

Martins et al. (2006), atribuíram maior efeito inibitório de BAL cultivados em anaerobiose na inibição de E. faecalis. Aqui, o maior efeito inibitório foi dado por linhagens de lactobacilos em aerobiose. Enquanto a linhagem $B$. lactis apresentou maior efeito antagônico quando cultivada em anaerobiose.

Para todos os experimentos um controle sem inóculo foi utilizado para observação do possível efeito dos constituintes do meio de cultura sobre o desenvolvimento dos microrganismos em teste, porém não se observou qualquer efeito inibidor dos microrganismos indicadores nesta condição (Tabelas 1, 2 e Figura 3).

O antagonismo promovido por L. plantarum DCTA 8420 e B. lactis DCTA 8724 isoladas do intestino humano, são encorajadores, e tem um papel importante na ciência e tecnologia de alimentos, pois está diretamente relacionado à capacidade de produzir e tolerar concentrações elevadas de ácidos ou bacteriocinas, permitindo a inibição de outros microrganismos e favorecendo a competição num dado ecossistema. Isso reafirma a importância de se isolar e caracterizar estes microrganismos, sobretudo, com relação à saúde pública, já que a habilidade de produzir compostos antimicrobianos e promover a atividade antagonista contra patógenos potencializa a caracterização destes como linhagens probióticas.
Figura 3. Halos de inibição com cultivo de L. plantarum DCTA 8420 em agitação (Ae), estático (An), inibindo S.aureus FRI 196e, e (C) controle com meio de cultivo concentrado, não inoculado.

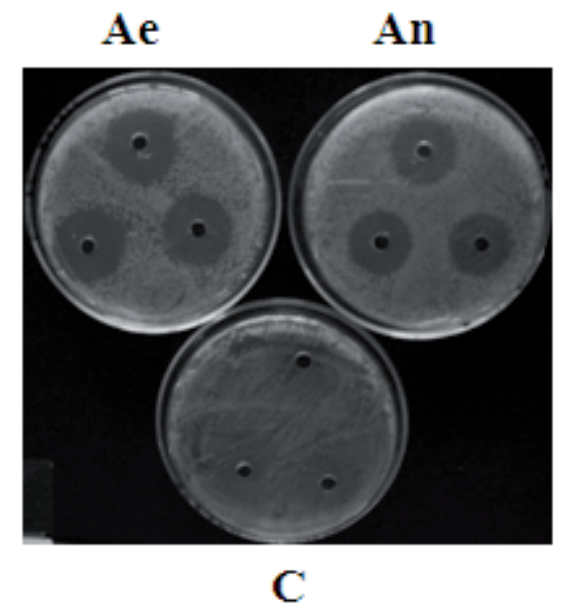

Fonte: Elaboração dos autores.

A utilização de culturas lácticas, que apresentam comprovada atividade antimicrobiana, na produção de alimentos fermentados torna esses produtos mais seguros ao consumidor, bem como aumentam a sua vida de prateleira, uma vez que inibem o crescimento de microrganismos deteriorantes e/ ou patogênicos. Quando estas linhagens exibem também outras características probióticas, o potencial para aplicação dos mesmos na indústria de alimentos é ampliado, o que favorece tanto as pesquisas acadêmicas quanto o desenvolvimento de produtos em nível industrial.

\section{Agradecimentos}

Os autores agradecem à C. Hansen Brasil pela doação da cultura LA5, à Prof ${ }^{\mathrm{a}} \operatorname{Dr}^{\mathrm{a}}$ Tereza Cristina R. M. Oliveira pela doação das bactérias patogênicas e ao Conselho Nacional de Desenvolvimento Científico e Tecnológico - CNPq, Processo: 140352/2008-2 pela bolsa de doutorado de G.A.N.C. 


\section{Referências}

AKIMOV, V. N.; SIDARENKA, A. V.; NOVIK, G. I. Application of molecular methods to classification and identification of bacteria of the genus Bifidobacterium. Microbiology, Spencers Wood, UK, v. 77, n. 3, p. 251260, 2008.

BEVILACQUA, L.; OVIDI, M.; DI MATTIA, E.; TROVATELLI, L. D.; CANGANELLA, F. Screening of Bifidobacterium strains isolated from human faeces for antagonistic activities against potentially bacterial pathogens. Microbiology Research, Copenhage, v. 158, n. 2, p. 179-185, 2003.

BRASHEARS, M. M.; DURRE, W. A. Antagonistic action of Lactobacillus lactis toward Salmonella spp. and Escherichia coli $\mathrm{O} 157: \mathrm{H} 7$ during growth and refrigerated storage. Journal of Food Protection. Des Moines, v. 62, n. 11, p. 1336-1340, 1999.

BROMBERG, R.; MORENO, I.; DELBONI, R. R.; CINTRA, H. C. Características da bacteriocina produzida por Lactococcus lactis ssp. hordniae CTC 484 e seu efeito sobre Listeria monocytogenes em carne bovina. Ciência e Tecnologia de Alimentos, Campinas, v. 26, n. 1, p. 135-144, 2006.

CHIODA, T. P.; SCHOCKEN-ITURRINO, R. P.; GARCIA, G. R.; PIGATTO, C. P.; RIBEIRO, C. A. M.; RAGAZZANI, A. V. F. Inibição do crescimento de Escherichia coli isolada de queijo "Minas Frescal" por Lactobacillus acidophilus. Ciência Rural, Santa Maria, v. 37, n. 2, p. 583-585, 2007.

CLIVER, D. O.; MARTH, E. H. Preservation, sanitation and microbiological specifications for food. In: CLIVER D. O. (Ed.). Foodborne disease. $2^{\text {nd }}$ ed. California, Academic Press, 1990. cap. 4, p. 85-106.

CLOSE, W. H. Producing pigs without antibiotic growth promoters. Advanced in Pork Production, Edmonton, v. 11, p. 47-56, 2000.

CONDON, S. Responses of lactic acid bactéria to oxygen. FEMS Microbiology Reviews, Lausanne, v. 46, n. 3, p. 269-280, 1987.

COSTA, G. N.; VILLAS-BÔAS, G. T.; VILLAS-BOAS, L. A.; MIGLIORANZA, L. H. S in silico phylogenetic analysis of lactic acid bacteria and new primer set for identification of Lactobacillus plantarum in food samples. European Food Research Technology, v. 233, n. 2, p. 233-241, 2011.

GARCIA, S. Isolamento e caracterização de bactérias lácticas para uso como probiótico. 1999. Tese (Doutorado em Ciência de Alimentos) - Universidade Estadual de Londrina, Londrina.
GOMES, A. M. P.; MALCATA, F. X. Agentes probióticos em alimentos: aspectos fisiológicos e terapêuticos e aplicações tecnológicas. Boletim Biotecnologia, Lisboa, n. 64, p. 12-22, 1999.

GUEDES NETO, L. G.; SOUZA, M. R.; NUNES, A. C.; NICOLI, J. R.; SANTOS, W. L. M. Atividade antimicrobiana de bactérias ácido-lácticas isoladas de queijos de coalho artesanal e industrial frente a microrganismos indicadores. Arquivos Brasileiros de Medicina Veterinária e Zootecnia, Belo Horizonte, v. 57, p. 245-250, 2005. Suplemento 2.

HOLZAPFEL, W. H.; STILE, M. E. Lactic acid bacteria of foods and their current taxonomy. International Journal of Food Microbiology, Torino, v. 36, n. 1, p. 1-29, 1997.

JACOBSEN, C. N.; NIELSEN, V. R.; HAYFORD, A. E.; MØLlER1, P. L.; MICHAELSEN, K. F.; PÆRREGAARD, A.; SANDSTRÖM, B.; TVEDE, M.; JAKOBSEN, M. Screening of probiotic activities of forty-seven strains of Lactobacillus spp. by in vitro techniques and evaluation of the colonization ability of five selected strains in humans. Applied and Environmental Microbiology, Washington, v. 65, n. 11, p. 4949-4956, 1999.

JIN, L. Z.; HO, Y. W.; ABDULLAH, N.; JALALUDIN, S. Probiotics in poultry: modes of action. World's Poultry Science Journal, New Zealand, v. 53, n. 4, p. 351-363, 1997.

JIN, L.; MARQUARDT, R. R.; BAIDOO, S. K. Inhibition of enterotoxigenic Escherichia coli K88, K99 and 987P by the Lactobacillus isolates from porcine intestine. Journal of the Science Food and Agriculture, Davis, v. 80 , n. 5, p. 619-624, 2000.

LAHTINEN, S. J.; JALONEN, L.; OUWEHAND, A. C.; SALMINEN, S. J. Specific Bifidobacterium strains isolated from elderly subjects inhibit growth of Staphylococcus aureus. International Journal of Food Microbiology, Torino, v. 117, n. 1, p. 125-128, 2007.

MADERA, C.; GARCÍA, P.; JANZEN, T.; RODRÍGUEZ, A.; SUÁREZ, J. E. Characterisation of technologically proficient wild Lactococcus lactis strains resistant to phage infection. International Journal of Food Microbiology, Torino, v. 86, n. 3, p. 213-222, 2003.

MARTINS, A. D. O.; MENDONÇA, R. C. S.; SILVA, D. L.; RAMOS, M. S.; MARTINS, M. C.; DONZELE, J. L.; ANDRADE, N. J. A. Resistência de bactérias lácticas, isoladas de fezes de suínos e sua capacidade antagônica frente a microrganismos indicadores. Revista de Ciências Agroveterinárias, Lages, v. 5, n. 1, p. 53-59, 2006. 
MENÉNDEZ, S.; GODÍNEZA, R.; HERMIDAB, M.; CENTENOC, J. A.; RODRÍGUEZ-OTERO, J. L. Characteristics of "Tetilla" pasteurized milk cheese manufactured with the addition of autochthonous cultures. Food Microbiology, Illinois, v. 21, n. 1, p. 97104, 2004.

NAIDU, A. S.; CLEMENS, R. A. Probiotics. In: In: NAIDU, A. S. Natural food antimicrobial systems. Boca Raton: CRC Press, 2000. cap. 17, p. 431-462.

NATIONAL COMMITTEE FOR CLINICAL LABORATORY STANDARDS - NCCL. Clinical and laboratory standards institute. Performance standards for antimicrobial susceptibility testing; Fifteenth Informational Supplement, M100- S15, Wayne, PA. 2005 .

PEREIRA, V. G.; GÓMEZ, R. J. H. C. Atividade antimicrobiana de Lactobacillus acidophilus, contra microrganismos patogênicos veiculados por alimentos. Semina: Ciências Agrárias, Londrina, v. 28, n. 2, p. 229240, 2007.

POZZA, M. S. S. Análise da variabilidade genética, susceptibilidade a condições do trato gastrointestinal e fermentação de oligofrutose, inulina e goma acácia por isolados de lactobacilos. 2006. Tese (Doutorado em Ciência de Alimentos) - Universidade Estadual de Londrina, Londrina.
PRASAD, M. M.; GHODEKER, D. R. Antimicrobial activity of lactobacilli isolated from fermented milk products. Cultured Dairy Products Journal, Washigton, v. 26, n. 2, p. 22-28, 1991.

SAKAMOTO, M.; KOMAGATA, K. Aerobic growth of and activities of NADH oxidase and NADH peroxidase in lactic acid bacteria. Journal of Fermentation and Bioengenering, Ishikawa, v. 82, n. 3, p. 210-216, 1996.

SCHILLINGER, U.; KARL LUCKE, F. Antibacterial activity of Lactobacillus sake isolated from meat. Applied and Environmental Microbiology, Washington, v. 55, n. 8, p. 1901-1906, 1989.

URAZ, G.; SIMSEK, H.; MARAS, Y. The inhibitory effects of Lactobacillus casei and Lactobacillus helveticus on Bacillus species isolated from raw milk in various salt concentrations. International Journal Dairy Technology, Oxford, v. 54, n. 4, p. 146-150, 2001.

VAUGHAN, E. E.; CAPLICE, E.; LOONEY, R. Isolation from food sources, of lactic acid bacteria that produced antimicrobials. The Journal of Applied Bacteriology, Oxford, v. 76, n. 2, p. 118-123, 1994.

WALKER, W. A.; DUFFY, L. C. Diet and bacterial colonization: role of probiotics and prebiotics. The Journal Nutritional Biochemistry, Lexington, v. 9, n. 12, p. 668-675, 1998. 